\title{
Thoughts on the Integration of National Folk Music into Children's Music Education
}

\author{
Xiaoxiao Fan \\ Chongqing University of Education, Chongqing, 400000, China
}

Keywords: Folk music, Young children, Music education.

\begin{abstract}
In view of the in-depth implementation of policies and guidelines in various areas of education in China in recent years, the development of children's music education has also witnessed a prosperous and good development. However, children's music education content today is often based on the Western music culture, which is the main content, however, China's national folk music content is very small. Inheriting and promoting our country's folk music culture and integrating it into our country's children's music education is of great value for enhancing the soft power of our country's culture. This paper discusses the necessity of integrating ethnic folk music into children's music education, enumerates the main methods of integrating ethnic folk music into children's music education, and puts forward some countermeasures to further promote the integration of national folk music into children's music education.
\end{abstract}

\section{Introduction}

In recent years, with the continuous development of the global economy, people's demand for culture has become more intense. In the development of countries around the world, the influence of national culture has become particularly important in competition. China is a large country with many ethnic groups. The people of all ethnic groups have created splendid ethnic and folk culture on this beautiful land, and they have also developed extremely rich ethnic and folk music resources. Today, there are two major trends in the development of children's music education in China: First, kindergartens, which are mainly represented by economically developed regions, have not only good hardware facilities and equipment, but also generally introduce Western music education methods. Second, kindergartens represented by relatively economically underdeveloped regions, because they have the concept of primary schooling and lack of qualified teaching staff, lead to music education that is too scattered and fragmented. The two types of preschool children's music education are now dependent on cultural soft power, which is not conducive to the sustainable development of children's music education. Therefore, we should actively explore the basic orientation of the promotion of cultural soft power, try to integrate ethnic folk music into children's music education, and thus develop a new type of early childhood education development.

\section{The Necessity of Integrating National Folk Music into Children's Music Education}

Ethnic folk music is preserved by the long-term development of the nation for hundreds or even thousands of years. It can directly represent the national culture and is a music culture with the strongest vitality and long-term influence. The purpose of this music education is necessary for students to better understand our country's very long tradition of culture. This is also an important basis for the inheritance of our national folk music culture. Through the implementation of national folk music education for young children, it can help them to improve national pride and self-confidence. Early childhood educators are responsible for the use of education and scientific research to enable students to pass on ethnic folk music. Therefore, the integration of ethnic folk music into children's music education is imminent. 


\section{The Main Methods of Integrating Ethnic Folk Music into Children's Music Education}

The first is to integrate ethnic folk music into singing. Singing is one of the most important aspects of children's music activities. It not only can greatly enrich children's emotional experience and cultivate their sentiments, but also can improve their children's intelligence. Singing is an indispensable and important activity in the daily life of many ethnic minorities in our country. In particular, children's songs of ethnic minorities are not only very broad in subject matter, but also rich in content, and can teach young children to distinguish right from wrong, and are therefore deeply loved by young children. The second is to integrate ethnic folk music into music appreciation activities. Music appreciation activities can enhance the children's appreciation and aesthetic ability, expand the children's vision, and enrich the children's experience of music appreciation, so that they initially feel the beauty and beauty of the fun. The inclusion of ethnic folk music in the appreciation of young children's music not only expands the musical outlook of the young children, but also allows them to feel and appreciate the unique beauty of folk folk music. At the same time, there are some ethnic folk songs and dances that are so difficult that even young children cannot grasp them completely, so teachers can use it as a content of young children's music appreciation. It should be pointed out that the enthusiasm for early childhood music appreciation is mainly due to the curiosity of novelties that have never been seen before. Therefore, teachers should make full use of multimedia courseware to demonstrate the visual presentation of texts and images so as to provide more for young children. Good learning resources mobilize children's visual and auditory organs, and push the aesthetic experience to a new climax. The third is to integrate ethnic folk music into musical performances. Musical instrument playing is not only an important part of music teaching for young children, but also can not only develop children's ability to hear rhythm and timbre, but also excavate their better cooperation consciousness and coordination ability. Rhythm includes rhythm, dance and other rhythmic activities. The goal of teaching is to make young children willing to participate in national folk music activities. They like to use simple actions to reflect the emotions of national folk music, and experience the joy of using gestures, expressions, and gestures.

\section{Some Countermeasures to Further Promote the Integration of Ethnic Folk Music into Children's Music Education}

\subsection{Use Cultural Soft Power to Create Cultural Consciousness}

The development of cultural soft power must depend on everyone's cultural awareness, and this cultural awareness should start from kindergarten. The main manifestation of behavior in cultural awareness is to participate in it autonomously. In the past, children's music education is often in the most important position. Because young children still have full autonomy, they can only passively participate in music teaching. In the process of implementing national folk music education, it is very necessary to establish cultural awareness. This must allow young children to participate in teaching activities more consciously and autonomously. This requires music teachers to choose more teaching activities that are more participatory. , so that children can take the initiative to participate in them, for example, can take the game teaching methods, situational teaching methods. It is necessary to fully integrate related courses and integrate the many methods of music teaching in the early childhood education process, rather than just a single singing class and instrumental music teaching. Of course, the exploration of elementary creative education activities can also be carried out. In such teaching activities, young children will not participate consciously in order to achieve the purpose of improving cultural awareness.

\subsection{Carefully choose the appropriate ethnic and folk music teaching content}

For ethnic folk music to enter the kindergarten teaching, how to choose reasonable teaching content directly involves the effectiveness of children's music learning. In the long history of musical cultural changes, national folk music has already had the characteristics of five-tone harmony, unique tone, and a large number of outstanding works have emerged, thus providing a very rich educational 
material for early childhood music teaching. However, the physical and mental development of young children will also determine that a large number of national and folk music are not suitable for kindergarten music education classes. For example, even the part of national folk music that has a relatively wide range of sound and is too dramatic. Therefore, in the selection of children's music education content, we should completely eliminate the far-fetched issues, in the selection should be consistent with the mental age characteristics of young children, so as to better promote the sustainable development of ethnic folk music. In the singing and singing process, based on the children's physical and mental characteristics, we must use folk songs that are narrow in scope, not large in degree of jump, and short in structure. It can be said that ethnic folk music has provided a lot of resources for the teaching of infant music, and it should also be based on the physical and psychological development characteristics of young children to choose between, and timely implementation of a reasonable adaptation, so as to find the use of children's music education for the national folk music teaching The reasonable approach.

\subsection{Conduct Characteristic Projects to Create Good Cultural Situations}

There are many types of ethnic folk music in our country, and the style is also different. In order to enhance the local cultural soft power, we should be rich in characteristics in terms of competitiveness, so that we can use special projects to create a better cultural situation. At present, in our country's kindergartens, there has been a polarization in the introduction of national folk music teaching. On the one hand, urban kindergartens have very good conditions for hardware facilities, and cultural awareness is quite strong. However, because of the lack of the foundation of national folk music culture, it is difficult to implement more teaching of ethnic and folk music content. On the other hand, although township and kindergartens have very good basic conditions for ethnic folk music, especially with very rich folk artist resources, it is very difficult to implement it because of insufficient hardware resources and insufficient awareness. . In this context, it is necessary to implement the strategy of promoting development with featured projects. Among the teaching practices, specific projects that are suitable for the kindergarten's objective conditions should be thoroughly explored in order to develop systematically. For those kindergartens with better conditions, it is also possible to put a part of the teaching programs that require high software and hardware requirements. If specialization projects among ethnic folk music are to be implemented, the requirements for hardware facilities are quite high, so that the featured projects can be implemented in kindergartens with better conditions in the city. For the remote rural areas where the economy is not well-developed, the folk and folk music in these areas are preserved very well. These kindergartens can fully develop and utilize the local folk music. This part is simple and easy, and has a deep cultural foundation. National folk music can be included in the application of specialization projects.

\subsection{Explore and promote teaching through multi-linkage exploration}

The development of cultural soft power is the need for the rejuvenation of Chinese culture. Therefore, in the current international environment, all sectors of society should regard cultural soft power as an important goal and driving force for their own development. Under this cultural background, in order for children's ethnic and folk music education to achieve development, it is possible and necessary to embark on a path of harmonious development and use various social resources to promote better development. The first is to invite ethnic folk music institutions to enter kindergartens and scientifically apply various social resources. As the social division of labor tends to be specialized, most of the folk folk music in our country is no longer just word-of-mouth, but is managed and developed by specialized music groups. Under the reform of the socialist economic system with Chinese characteristics, a large number of music groups have transformed from the nature of state-owned enterprises into pure social groups. This change has promoted the socialization of music groups and they have become more aware that they should take up a good society. The sense of responsibility has made it possible for ethnic folk music groups to introduce kindergarten teaching. In teaching practice, it can be implemented in the form of cooperation between teachers and national 
folk music societies. It is also possible to negotiate with societies so that young children can fully integrate themselves into musical performances and gain the most direct musical feeling in the process of participation. The second is to share the cultural resources of relevant departments to promote cultural prosperity. In addition to folk artists and social music groups, the main body of national folk music protection and inheritance should also include some government-style cultural institutions, such as cultural centers, art galleries, and museums. The above government-based cultural institutions have a considerable number of ethnic and folk music resources, and they also have some administrative methods to promote the development of national folk music, and apply the above resources and methods to the teaching of national folk music for young children. It will not only promote the sustainable development of children's music education, but also achieve the goal of promoting the current cultural prosperity. At the same time, it should also be able to rely on the administrative forces of the cultural authorities to promote better development of national folk music teaching. The third is to promote homebuilding together to form a full range of cultural infiltration. The prominent role of home-school co-education in promoting children's development has been identified in the kindergarten education program in China. Today, a considerable number of young children in China belong to the intergenerational education, or live together with grandparents and grandchildren. Older people are often very fond of and familiar with ethnic folk music, leading to a considerable foundation for national folk music education. Because of the expressional and non-semantic nature of music education, it is not the case that cognition is the main subject in the classroom teaching of children. It is also necessary for the children to be able to feel the beauty of national folk music in our country subtly for their music. The formation of literacy lays a good foundation.

\section{Summary}

In summary, national folk music has always been one of the most compelling aspects of China's folk and cultural parks. As China enters a new era of socialism with Chinese characteristics, more and more ethnic folk music has laid a solid foundation for promoting the promotion of China's cultural soft power. From the early childhood education, trying to launch an effective channel for the implementation of national folk music education is not only very beneficial to promote the reform of infant music education in China, but also very beneficial to improve the competitiveness of traditional Chinese culture. The author firmly believes that with the increasing integration of ethnic folk music into early childhood education, it will surely become an important way to promote the new development of China's early childhood music education.

\section{Acknowledgement}

This research was financially supported by the Development and Utilization of Characteristic Music Course Resources for Kindergartens of Tujia Areas in Chongqing in the Background of Urban and Rural Co-ordination (Grant NO. KY201713B). And 2017 School-level Scientific Research Project of Chongqing Second Normal University, General Year Project.

\section{References}

[1] Zhang Li. The Significance and Effect of the Inheritance of Ethnic Folk Music in Preschool Music Education, Journal of Lanzhou University of Arts and Science (Social Sciences Edition), 2014(6).

[2] Xu Jing, Cui Yongping. On the integration of national folk music and early childhood education from the cultural point of view, Nature Boy, 2014(9).

[3] Wang Haoyu. The Significance of National Folk Music Injection into Kindergarten Education Practice, Education Forum, 2015, (21). 
[4] Jiang Fan. The Penetration of Ethnic Folk Music in Preschool Music Education, Art Review, 2017(4).

[5] Li Zhonglin. The Application of Guizhou Folk Music Element in the Creation of Children's Songs, Theatre Home, 2017(5). 